\title{
Interference calculations for aeronautical communications using cells in Greek airspace.
}

\author{
Evangelos Kokkinos ${ }^{1}$, Ilias Peteinatos ${ }^{1}$ and Rajagopal Nilavalan ${ }^{2}$ \\ ${ }^{1}$ Electronic Engineers of TEI of Crete \\ Chania, Greece \\ ekokkinos@chania.teicrete.gr \\ ${ }^{2}$ Department of Electronic and Computer Engineering of Brunel University, \\ London, UK
}

\begin{abstract}
The aim of this work is to study the capacity of the three dimensional cellular Air-to-Ground system. Calculations have been done through simulations of the Outside Cell Interference Factor (OCIF), for reverse and forward link, by using seven rings of interfering cells around the desired cell, for various values of the maximum height of the cell and its radius. A Case Study for the major Greek airports has been made in which the number of the users per cell is being calculated for voice service of $12.2 \mathrm{kbps}$.
\end{abstract}

Keywords: WCDMA, Air to Ground, Ground to Air communications, OCIF, interference analysis, capacity, RLOS.

\section{INTRODUCTION}

Until the present day, the use of mobile phones and other electronic devices is prohibited during flight time for security reasons. However, through the course of time and the increase in the need for communication for personal and professional reasons, the use of electronic devices will be allowed making flight time more pleasant and more constructive for the passengers.

The problem which is being studied in this paper concerns the communications between aircraft passengers with the rest of the world through their mobile phones or through internet. Moreover, today, the current systems of Air Traffic Management (ATM) and Air Traffic Control (ATC) have already reached peak conditions in some major airports due to the increasing numbers of flights in the last years. Therefore, the suggested cellular Ground to Air system which introduced by Matolak in 2000 [1], can be another candidate technology for communication between aircrafts and the terrestrial systems of management and control of the safety of flights, which through the present technologies have reached saturation point. Our study is focused in the capacity of the suggested system [1].

As is already mentioned, first Matolak in 2000 [1] worked on this problem, he suggested a three-dimensional cellular cell system for the Air-to-Ground communication. He calculated the interference from the users outside the cell it serves (outside-cell interference factor) of a CDMA system, which comprises of uniformly distributed terrestrial base stations and users who are in aircrafts. It is known that the capacity of a CDMA system is generally inversely proportional of the outside-cell interference factor. Also Matolak shows that the outside interference factor is greater in his model than in the respective terrestrial transmission models and it depends logarithmically on the radius and the height of the cell. Zhou et al. in 2005 [2] expanded Matolak's work to include data packets transmission's performance in the forward link and the capacity, the throughput and the delay of the system were calculated. Moreover Zhou et al. in 2007 [3] studied the impact of the imperfect power control in CDMA Air-toGround communications systems. Assuming that the imperfect power control follows log-normal statistics, they studied the capacity and the possibility of non-function (outage probability) of these systems. The numerical results showed that the CDMA Air-to-Ground communication systems are sensitive even in minor errors of the power control. Since the power control in the WCDMA (Wideband Code Division Multiple Access) is executed 1500 times per sec both in the $\mathrm{UL}$ and the DL, is expected to be a less vulnerable system in errors of power control, especially in the DL compared with the IS-95 system in which the power control is done 800 times/second in the UL, while in the DL it is a lot more slower.

In order to solve the problem of saturation of the existing technologies for the ATM and ATC the STAR project [4] was implemented, in which the performance of the WCDMA system applied in ATM communications was tested by using a demonstrator. The results of the simulations showed that with the use of the WCDMA system in ATM communications we have an increase of the capacity in relation to the existing ATM system VDL mode 2. Most recently, Smida et al. [5] provided analytical bounds for the interference between the cells for ground to airborne cellular communication systems, assuming a three-dimensional hexagonal cell pattern. She also assumes that there is line of sight channel without shading and ideal antenna patterns. She also provides numerical results which show that the bounds are very tight. An implementation which could be accomplished according to Smida is an Evolution Data Only system (EV-DO) Release 0 and Revision $\mathrm{A}$, in which the channels have bandwidth $1.25 \mathrm{MHz}$ both in the forward and the reverse link.

In this work, the WCDMA was regarded as a possible solution due to its high spectral efficiency and due to the fact that there has been more than a decade of experience since the development of the terrestrial WCDMA systems worldwide. A 
capacity study of the airspace of Greece will be given, so that the aircraft passengers could use their mobile phones or the internet during their flights.

The main contribution of this work is the calculation of the number of voice users in a Air-to-Ground communication systems cell by using closed form equation through the use of load factor, activity factor and sectoring gain. Moreover, a Case Study of the capacity of the Air-to-Ground system for the airports of Greece for voice service of $12.2 \mathrm{kbps}$, is provided. The number of users per cell is calculated for the three major airports of Greece, using a cell radius of $175 \mathrm{~km}$.

The paper is organized as follows: in the next section the Problem Formulation is presented. In next section the algorithm used to calculate the OCIF is explained for both links and its results are given for different values of height and radius of the cell. In the subsequent section, the case study of the capacity of the Air-to-Ground system for the airports of Greece is shown. Finally, the conclusions are presented.

\section{PROBLEM FoRMULATION}

The major limiting factor of the capacity of a cellular system is the existence of interference and therefore, there needs to be a quantification of this interference. According to Viterbi [6], the capacity for the reverse channel (mobile station to base station) is:

$$
\mathrm{M}=\frac{\mathrm{w}_{\gamma} / \mathrm{K}_{\mathrm{b}}}{\mathrm{E}_{\mathrm{b}} / \mathrm{N}_{\mathrm{o}}} \frac{1}{1+\mathrm{f}_{R}}
$$

where $M$ is the number of active users, $W / R_{b}$ is the bandwidth to data rate transmission ratio, $\mathrm{E}_{\mathrm{b}} / \mathrm{N}_{\mathrm{o}}$ is the ratio of the energy per bit of transmitted information to the spectral noise density and interference and $f_{R}$ is the outside cell interference factor.

In ground cellular systems, we use cells of regular hexagons. Their expansion for the modeling of the Air to Ground (ATG) communication would be the use of regular hexagonal prisms. For mathematical simplicity, instead of using hexagonal prism cells we can use cylinder cells of the same height and volume, namely the base of the cylinder cells will have the same area with a regular hexagon. Matolak's three-dimensional model is being used; see Figure 1, where there is Line of Sight (LoS) without shading. The transmission path loss of the ATG /GTA channel, is inversely proportional with the square of the distance from the transmitter (like free space model).

The base stations, which will be used in this model, will be terrestrial facilities which will be distributed in a similar hexagonal cellular pattern, just like terrestrial cellular systems. From this hexagonal pattern we will retain the positions of the base stations. The base stations will be placed in these positions in the Air to Ground model, which will be lain in the centre of the bottom base, of each cylinder. The mobile stations are airborne and are uniformly distributed in the volume of each cell. Consequently, the hexagonal cell of the conventional terrestrial model is matched with a cylinder in the Air Ground model of the same volume with that of the hexagonal prism. Given that the hexagonal prism would have
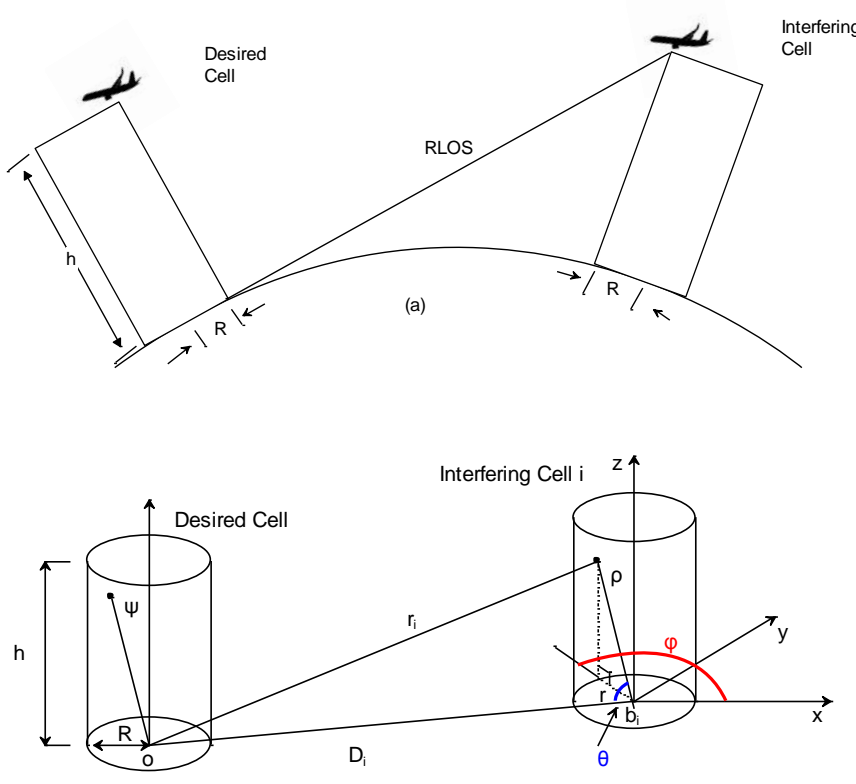

(b)

Fig. 1. The system Air to Ground - Reverse link (a) cross-section view (b) 3D representation.

the same height with the cylinder, in order to have the same volume, they should also have the same base area. Thus, $R_{\text {circle }}=0.9097 R_{\text {hex }}$ where $R_{\text {cicle }}$ is the circular base radius and $R_{h e x}$ is the hexagonal base radius.

Suppose that an aircraft is flying at the height $\mathrm{z}$ from the surface of the earth. The distance RLOS (radio line of sight) to the horizon of the earth, for this height $\mathrm{z}$, can be estimated as

$$
\operatorname{RLOS}(\mathrm{z})=\sqrt{\mathrm{z}^{2}+2 \mathrm{R}_{\mathrm{t}} \mathrm{z}} \approx \sqrt{2 \mathrm{R}_{\mathrm{t}} \mathrm{z}}
$$

where $R_{t}$ is the effective Earth's radius which is $\mathrm{R}_{\mathrm{t}}=4 / 36378.135 \mathrm{Km}$.

Let's assume that the aircrafts are uniformly distributed in the volume of the cylindrical cell of maximum height $\mathrm{H}_{\max }$ and each aircraft will be connected to the nearest base station. Matolak [1] employed omni-directional antennas at the center of each cell. In this paper the model expanded for the more realistic case of the antenna systems with three sectors where there is sectoring gain, because the interference received from each sector will be the one third of the interference of the OMNI antennas. The implementation of sectors will be every 120 degrees. For simplicity reasons is assumed that the calculation of the OCIF, depends only with the distance from the base station and not by the relative angle. In order to find the capacity of ATG system, the OCIF $f_{R}$ for the reverse or uplink channel (mobile station to base station) is calculated and also the OCIF $f_{F}$ for the forward or downlink channel (base station to mobile station) is given. The factors $f_{R}$ and $f_{F}$ are used in evaluating the capacity per cell, namely in calculating the users per cell, in a CDMA system. 


\section{A. Reverse link}

Every transmission from one user outside the cell, increases the overall Interference. Taking into consideration the transmission path loss in the air - ground environment and therefore the fraction of the distances $\left(\frac{P}{r_{i}}\right)^{2}$, as in Figure 1 the following equation is obtained [equation (2) in 1],

$\mathrm{f}_{\mathrm{R}_{\mathrm{i}}}(\mathrm{h}, \mathrm{R})=\iiint_{V_{\mathrm{i}}}\left(\mathrm{P}^{\mathrm{P}} / \mathrm{r}_{\mathrm{i}}\right)^{2} \mathrm{I}\left(\mathrm{RLOS}(\mathrm{z})-\mathrm{r}_{\mathrm{i}}\right) \mathrm{p}(\mathrm{r}, \varphi, \mathrm{z}) \mathrm{r} \mathrm{dr} \mathrm{d} \varphi \mathrm{dz}$

where $\rho$ : the distance of an external mobile station to its own base station, $\mathrm{r}_{\mathrm{i}}$ : the distance of the external user which causes the interference to the base ' $o$ ', $I\left(\operatorname{RLOS}-r_{i}\right)$ : is the indicator function to the RLOS, so that when there is line of sight (LOS) between the interfering external user and the base station $o$, it should contribute in the total interference, while when there is no LOS, it will not contribute.

The density function of users $\mathrm{p}(\mathrm{r}, \varphi, \mathrm{z})=$ $1 /($ Cell Volume $)=1 / \mathrm{Vi}=1 /\left(\pi \mathrm{R}^{2} \mathrm{~h}\right)$ will be used as the spatial density of users, in which $h$ is the height of the cylindrical cell and $\mathrm{R}$ is its radius. This ensues the density of users $\mathrm{p}(\mathrm{r}, \varphi, z)$ is uniformly distributed, namely it is constant within the volume of the cylindrical cell. Moreover, due to the fact that it is a probability density function (pdf), the (triple) spatial integral in cylindrical coordinates should be equal with 1 .

$$
\begin{gathered}
\int_{0}^{\mathrm{h}} \int_{0}^{2 \pi} \int_{0}^{\mathrm{K}} \mathrm{p}(\mathrm{r}, \varphi, \mathrm{z}) \mathrm{rdrd} \varphi \mathrm{d} \mathrm{z}=1 \Rightarrow \\
\mathrm{p}(\mathrm{r}, \varphi, \mathrm{z}) \int_{0}^{\mathrm{h}} \int_{0}^{2 \pi} \int_{0}^{\mathrm{K}} \mathrm{rdrd} \varphi \mathrm{dz}=1 \Rightarrow \\
\mathrm{p}(\mathrm{r}, \varphi, \mathrm{z})=\frac{1}{\pi \mathrm{R}^{2} \mathrm{~h}}
\end{gathered}
$$

For the calculation of RLOS the height $\mathrm{z}$ in which the airplane flies will be used and not the height $h$ of the cylindrical cell that Matolak uses, because if there is LOS the indicator function I(RLOS $\left.(z)-r_{i}\right)$ will be one, while if there is no LOS it will be zero and this should solely depend on the height $\mathrm{z}$ in which the aircraft flies and not on the height $\mathrm{h}$ of the cell. $f_{R}$

The $\mathrm{f}_{\mathrm{R}_{\mathrm{i}}}$ is the contribution of the cell $\mathrm{i}$ (as in Figure 2.2) to

$$
\mathrm{f}_{\mathrm{R}}=\sum_{\mathrm{l}=1}^{168} \mathrm{f}_{\mathrm{R}_{\mathrm{i}}}(\mathrm{h}, \mathrm{R})
$$

It is assumed that the interference for every desired cell ' $\mathrm{o}$ ' will be estimated from the 168 cells that surround it, in 7 rings of the cellular pattern. As in [Fig. 4 of 5], in the first three rings that surround the central cell, which corresponds to the desired cell ' $\mathrm{o}$ ' of the Figure 1b: the first ring has 6 cells, the second 12 cells and the third 18 cells, the forth ring 24 cells, the fifth 30 cells, the sixth 36 cells, the seventh 42 cells. As it can be noticed in every following cell, the number of cells increases by 6 cells which surround the central cell.

The distance $r_{\mathbf{i}}$ is given by (see [5] and [7])

$$
r_{i}=\sqrt{D_{i}^{2}+r^{2}+2 r(x i c o s \varphi+\text { yisin } \varphi)+z^{2}}
$$

According to [8, equation.(8.14)] the relationship which derives for the number of users to the activity factor is found by solving for $\mathrm{M}$ (in the book it is symbolized with $\mathrm{N}$ )

$$
\mathrm{M}=\frac{\left(\mathrm{w}_{/ \mathrm{R}_{\mathrm{b}}}\right) \mathrm{n}_{\mathrm{UL}}}{\left(\mathrm{E}_{\mathrm{b}} / \mathrm{N}_{\mathrm{Q}}\right)} \cdot \frac{\mathrm{G}_{\mathrm{V}} \mathrm{G}_{\mathrm{A}}}{1+\mathrm{f}_{\mathrm{R}}}
$$

The $\mathrm{n}_{\mathrm{UL}}$ expresses the telecommunications load cell and takes values less than one. This is for reasons of practical implementation of receivers, for example, the receiver should have finite dynamic range and must be stable [6, page 204]. An indicative maximum values that can take the $\mathrm{n}_{\mathrm{UL}}$ is 0.9 [6]. $\mathrm{Gv}$ : is the gain due to voice or data activity $\mathrm{G}_{\mathrm{V}}=\frac{1}{\mathrm{w}}$, where $\mathrm{v}$ is the voice activity factor, a typical value is $v=3 / 8 . \mathrm{G}_{\mathrm{A}}$ : is the gain due to antenna sectoring. This gain is derived when a sector antenna is used.

\section{B. Forward link}

It is assumed that all the users transmit and receive at the same data rate $\mathrm{Rb}$, same number of users, $\mathrm{m}$, in each cell and the $\left(\frac{\mathrm{E}_{\mathrm{b}}}{\mathrm{N}_{\mathrm{a}}}\right)_{\text {eff }}$ is the same for all users (an average value) [1].

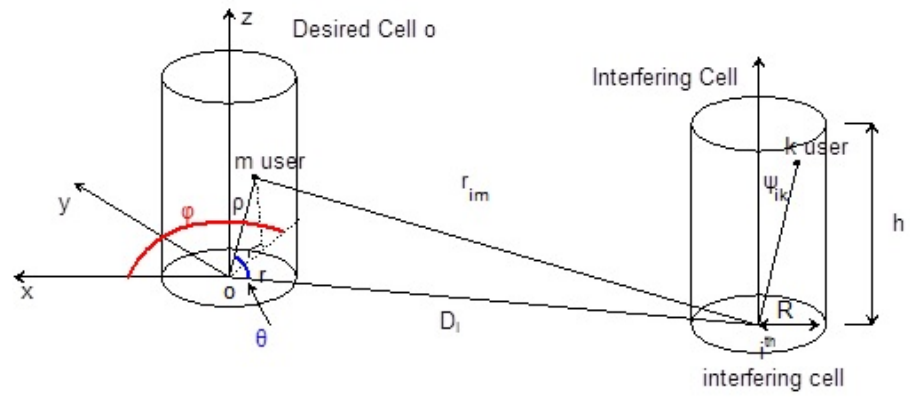

Fig. 2. Air - Ground model for forward link.

Since 168 cells surround in 7 rings the desired cell, the OCIF $\mathrm{f}_{\mathrm{F}}$ it is obtained

$$
\begin{gathered}
\mathrm{f}_{\mathrm{F}}=\sum_{\mathrm{i}=1}^{168} \mu_{\mathrm{i}} \\
\mu_{\mathrm{i}}=\mathrm{E}\left(\frac{1}{\gamma_{\mathrm{im}}^{2}}\right) \cdot \mathrm{E}\left(\psi_{\mathrm{ik}}^{2}\right)
\end{gathered}
$$

where, $\Psi_{\mathrm{ik}}$ is the distance between the i-interfering BS and the $\mathrm{k}$-th user of the $\mathrm{i}$-BS and $\mathrm{r}_{\mathrm{im}}$ is the distance between the $\mathrm{i}$ interfering BS and the user $\mathrm{m}$ in cell $\mathrm{o}$. Thus, the number of users is given

$$
\mathrm{M}=\frac{\left(W / \mathrm{R}_{\mathrm{b}}\right) \mathrm{n}_{\mathrm{DL}}}{\left(\frac{\mathrm{E}_{\mathrm{b}}}{\mathrm{N}_{\mathrm{a}}}\right)} \times \frac{\mathrm{G}_{\mathrm{V}} \mathrm{n}}{\mathrm{f}_{\mathrm{F}}}
$$

in which $\mathrm{n}$ is the number of the sectors and $\mathrm{n}_{\mathrm{DL}}$ is the corresponding to $\mathrm{n}_{\mathrm{UL}}$ load factor for down link (or forward link). The above is valid when each sector is considered as one cell. Equations (8) and (9) will be used for the calculation of $\mathrm{f}_{\mathrm{F}}$. So, from Fig. 2 by taking the triple integral on the cylindrical cell we have

$$
\begin{gathered}
\mathrm{f}_{\mathrm{Fi}}(\mathrm{h}, \mathrm{R})= \\
\int_{0}^{2 \pi} \int_{0}^{\mathrm{R}} \int_{0}^{\mathrm{h}} \frac{\mathrm{E}\left(\psi_{\mathrm{ik}}^{2}\right)}{\mathrm{r}_{\mathrm{im}}^{2}} \times \mathrm{I}\left(\mathrm{RLOS}-\mathrm{r}_{\mathrm{im}}\right) \times \mathrm{p}(\mathrm{r}, \varphi, \mathrm{z}) \mathrm{rdrd} \varphi \mathrm{dz}
\end{gathered}
$$

If equation (9) is used then we have 


$$
\begin{gathered}
\mu_{\mathrm{i}}=\mathrm{f}_{\mathrm{Fi}}(\mathrm{h}, \mathrm{R})= \\
\mathrm{E}\left(\Psi_{\mathrm{ik}}^{2}\right) \int_{0}^{2 \pi} \int_{0}^{\mathrm{k}} \int_{0}^{\mathrm{h}} \frac{1}{\mathrm{r}_{\mathrm{im}}^{2}} \times \mathrm{I}\left(\mathrm{RLOS}-\mathrm{r}_{\mathrm{im}}\right) \times \mathrm{p}\left(\mathrm{r}_{v} \varphi, \mathrm{z}\right) \mathrm{rdrd} \varphi \mathrm{dz}(12)
\end{gathered}
$$

Because, $\psi_{\text {ik }}$ in Fig. 2 is like $\rho$ in Fig. 1, we have,

$$
\mathrm{E}\left(\Psi_{\mathrm{ik}}^{2}\right)=\int_{0}^{2 \pi} \int_{0}^{\mathrm{k}} \int_{0}^{\mathrm{n}}\left(\mathrm{r}^{2}+\mathrm{z}^{2}\right) \cdot \mathrm{p}(\mathrm{r}, \varphi, \mathrm{z}) \mathrm{rdrd} \varphi \mathrm{dz}
$$

We finally obtain

$$
E\left(\Psi_{i \mathrm{k}}^{2}\right)=\frac{\mathrm{R}^{2}}{2}+\frac{\mathrm{h}^{2}}{\mathrm{a}}
$$

\section{NUMERICAL RESULTS}

\section{A. Illustration of Calculation Algorithm of $f_{R}$ and $f_{F}$}

Let's assume that we have a desired cell o (in the center of Fig. 3). Around the desired cell, we will assume seven rings, as it had been mentioned in previous section, from interfering cells. We are interested to calculate the distance D between the desired cell o and each interfering cell with the use of the shift parameters $(i, j)$ where $i, j$ are integers. Let's take a side, randomly, of the desired cell o. The vertical in this side is the axis movement of $i$, and the value of $i$, expresses how many cell positions we move over this axis. The direction of $\mathrm{j}$ derives, if from the direction of $i$, we turn for 60 degrees anticlockwise and the value of $\mathrm{j}$, expresses how many cell positions we move over this axis. The distance $\mathrm{D}$ between the desired cell and the interfering cell is given [9]

$$
\mathrm{D}=\sqrt{3} \sqrt{\left(\mathrm{iR}+\cos \left(60^{\circ}\right) \mathrm{j} \mathrm{R}\right)^{2}+\left(\sin \left(60^{\circ}\right) \mathrm{j} \mathrm{R}\right)^{2}}
$$

In the calculation o $\mathrm{f}_{\mathrm{R}}, \mathrm{f}_{\mathrm{R}_{\mathrm{i}}}$ is calculated using equation (3) for each one of the 168 interfering cells (seven rings) and then, equation (5) is employed to calculate $\mathrm{f}_{\mathrm{R}}$. The scanning mode of these 168 cells is done by taking each one of these six sides of the desired cell $o$, and we draw the vertical lines to these sides, the interfering cells are divided in six sectors as can be seen in Fig. 3. Without loss of generality we can focus on one of these six sectors, if for example we refer to the sector from 300 to 360 degrees (top left sector). The increase of degrees became clockwise, taking as a starting point the north semi axis, namely 0 degrees. In the first for loop the indicator $\mathrm{i}$ begins from the value 7 and in the second for loop the indicator $\mathrm{j}$ takes only zero value, see Fig. 3 .

Next, the indicator $\mathrm{i}$ is reduced by one and it becomes six, and the indicator $\mathrm{j}$ will take the values zero and one $\mathrm{i}=6$ and $j=0,1)$. Next, the indicator $i$ is reduced by one and it becomes five, and the indicator $\mathrm{j}$ will take values zero, one and two, $(i=5$ and $j=0,1,2)$. Using the same reasoning, the indicator $i$ is reduced each time by one and it ends up in its final value which is one and the indicator $\mathrm{j}$ will take the values $0,1,2,3$, 4, 5 and 6, see Fig. 4. It is obvious that in order to take the final value of $f_{R}$, it is enough to multiply $f_{R_{i}}$ by six, because for each cell in the mentioned sector, there are five similar interfering cells, one in each sector, in the other five sectors. In this way, scanning only the $28(=168 / 6)$ cells of one sector, we have calculated the total interference.

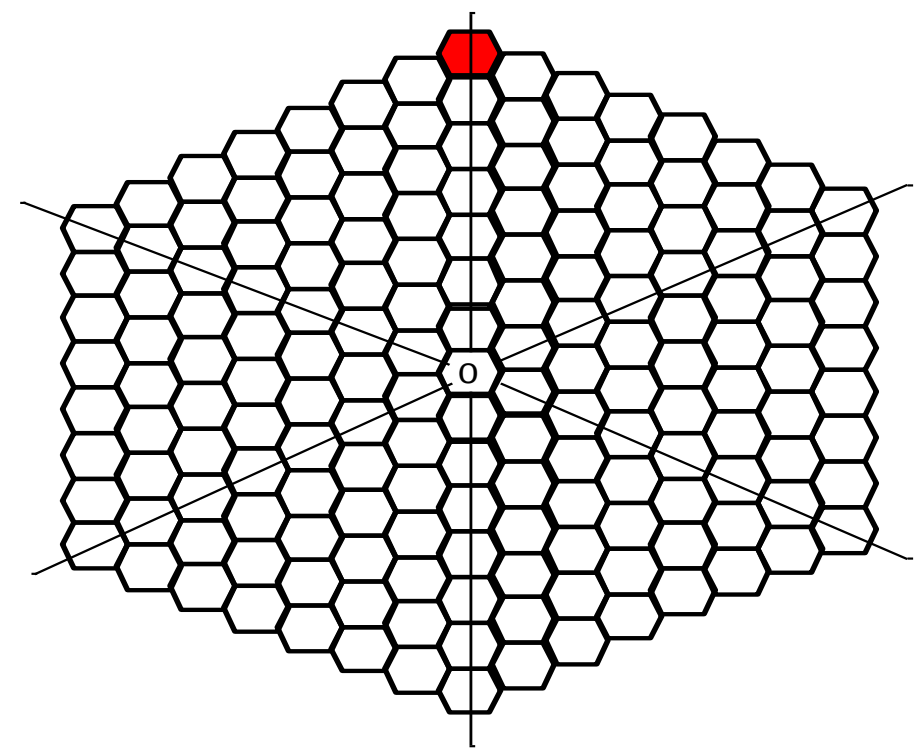

Fig. 3. The cell pattern with the central cell o which is the Desire cell and around it there are 7 rings of interfering cells. The cell pattern with the red marked interfering cell ( shift parameters $i=7$ and $j=0$ ).

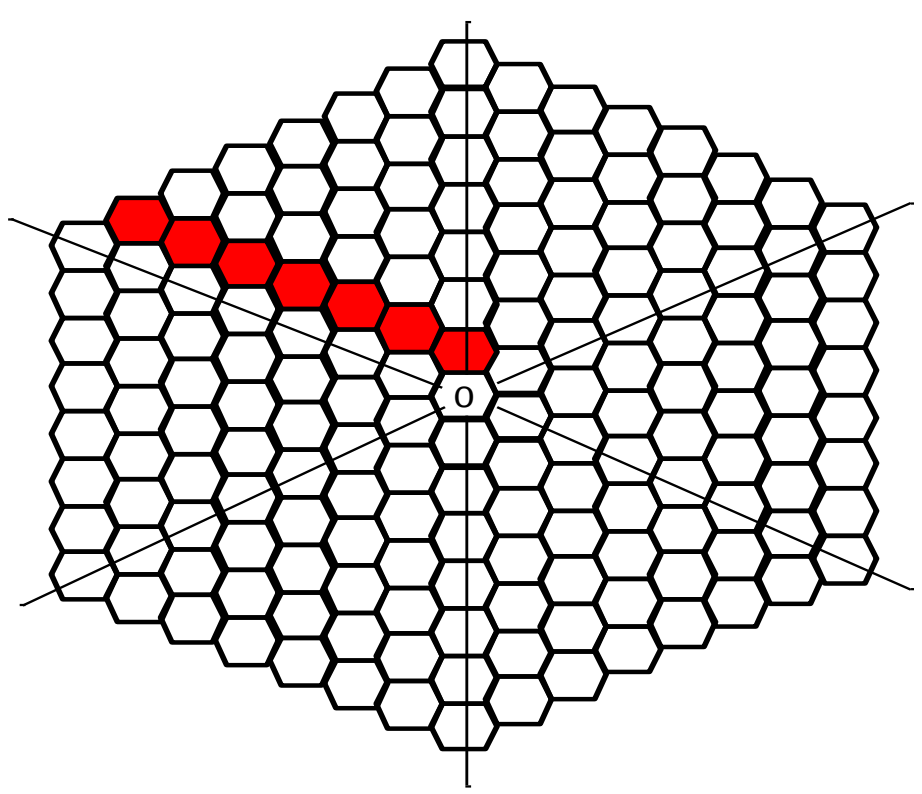

Fig. 4. The cells pattern with the red marked interfering cells ( $\mathrm{i}=1$ and $\mathrm{j}=0,1,2,3,4,5,6)$.

\section{B. Results for the $f_{R}$}

In order to calculate OCIF fR the equations (2), (3), (4) and (5) are used and the model of Fig. 1b. Also employing the algorithm described previously, the OCIF is calculated for every interfering cell, for the pair of values $(R, h)$ where $R$ is the cell radius and $h$ is the maximum height of the cell. Fig. 5 shows the values of $f_{R}$ as a function of $h$ and $R$. 


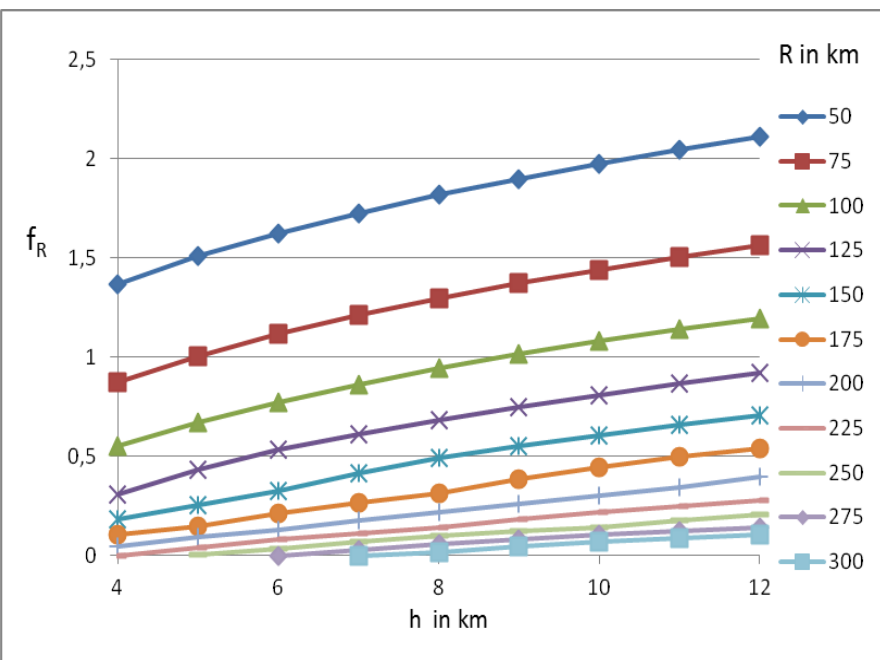

Fig. 5. The $f_{R}$ as a function of $h$ (step $1 \mathrm{~km}$ ). Each curve is for a specific value of $R=50 \mathrm{~km}, R=75 \mathrm{~km}, R=100 \mathrm{~km}, R=125 \mathrm{~km}, R=150 \mathrm{~km}, R=175 \mathrm{~km}$, $\mathrm{R}=200 \mathrm{~km}, \mathrm{R}=225 \mathrm{~km}, \mathrm{R}=250 \mathrm{~km}, \mathrm{R}=275 \mathrm{~km}$ and $\mathrm{R}=300 \mathrm{~km}$.

\section{Results for $f_{F}$}

The $\mathrm{f}_{\mathrm{Fi}}(\mathrm{h}, \mathrm{R})$ is calculated employing equations (4), (8), (12) and (14) for different values of $\mathrm{R}$ and $\mathrm{h}$ for each interfering cell. The scanning of 168 cells is done in the same way as it has been previously explained in the algorithm of the calculation of fR. Fig. 6 shows the values of $f_{F}$ as a function of $\mathrm{h}$ and $\mathrm{R}$.

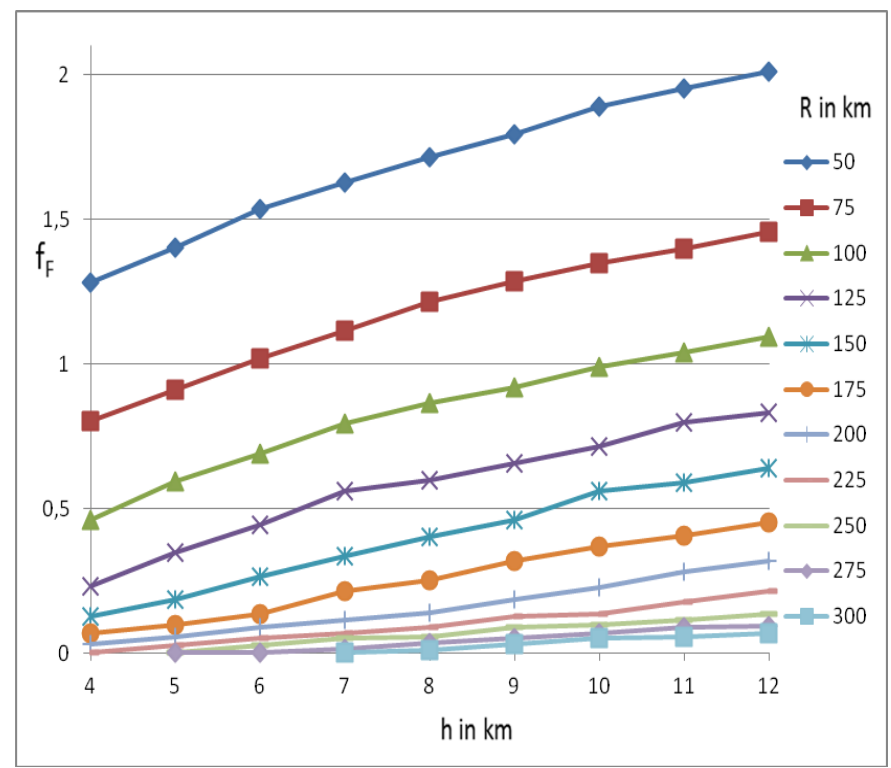

Fig. 6. The $\mathrm{f}_{\mathrm{F}}$ as a function of $\mathrm{h}($ step $1 \mathrm{~km})$. Each curve is for a specific value of $R=50 \mathrm{~km}, R=75 \mathrm{~km}, \mathrm{R}=100 \mathrm{~km}, \mathrm{R}=125 \mathrm{~km}, \mathrm{R}=150 \mathrm{~km}, \mathrm{R}=175 \mathrm{~km}$, $\mathrm{R}=200 \mathrm{~km}, \mathrm{R}=225 \mathrm{~km}, \mathrm{R}=250 \mathrm{~km}, \mathrm{R}=275 \mathrm{~km}$ and $\mathrm{R}=300 \mathrm{~km}$.

\section{The number of subscribers in Reverse link}

Number $\mathrm{M}$ of subscribers will be calculated for the height $\mathrm{h}$ of the cell and for various values of $\mathrm{R}$, both for forward and for reverse link, and the minimum $\mathrm{M}$ will be derived. In this way it will be found, which of the two links determines the capacity of the cell. So, $\mathrm{W}=3.84 \mathrm{Mcps}$ will be WCDMA chip rate, $R_{b}$ bit rate of user $=12.2 \mathrm{kbps}$, because it is assumed that all the subscribers will have only voice service and $\mathrm{n}_{\mathrm{UL}}=0.9$.

TABLE 1. M VOICE USERS IN REVERSE LINK, $\mathrm{R}_{\mathrm{b}}=12.2 \mathrm{Kbps}, \mathrm{W}=3.84 \mathrm{MCPS}$, ACTIVITY FACTOR V=0.545, $\mathrm{n}_{\mathrm{UL}}=0.9, \mathrm{E}_{\mathrm{b}} / \mathrm{N}_{\mathrm{O}}=7 \mathrm{~dB}$, FOR R=50, 75, 100, 125, 150, $175,200 \mathrm{KM}$, FOR VARIOUS VALUES OF h STARTING FROM 4 KM TO 12 KM

\begin{tabular}{|c|c|c|c|c|c|c|c|c|c|}
\hline \begin{tabular}{c} 
( $\begin{array}{c}\mathrm{h} \\
\mathrm{R} \\
(\mathrm{Km})\end{array}$ \\
\hline 5
\end{tabular} & 4 & 5 & 6 & 7 & 8 & 9 & 10 & 11 & 12 \\
\hline 50 & 131 & 123 & 118 & 114 & 110 & 107 & 104 & 102 & 100 \\
\hline 75 & 166 & 155 & 146 & 140 & 135 & 131 & 127 & 124 & 121 \\
\hline 100 & 200 & 186 & 175 & 166 & 160 & 154 & 149 & 145 & 141 \\
\hline 125 & 237 & 217 & 203 & 193 & 184 & 177 & 172 & 166 & 162 \\
\hline 150 & 263 & 247 & 234 & 219 & 208 & 200 & 193 & 187 & 182 \\
\hline 175 & 282 & 270 & 256 & 245 & 236 & 224 & 215 & 207 & 201 \\
\hline 200 & 297 & 284 & 275 & 265 & 255 & 246 & 239 & 231 & 222 \\
\hline
\end{tabular}

\section{E. The number of subscribers in Forward link}

In order to calculate the capacity in the forward link, the values of $\mathrm{E}_{\mathrm{b}} / \mathrm{N}_{0}$ used are derived from the respective values for the terrestrial systems from [Table 11.21 of 8], by adding $2 \mathrm{~dB}$ due to the Air-to-Ground model, as explained in [10]. Therefore, $\frac{\mathrm{E}_{\mathrm{b}}}{\mathrm{N}_{\mathrm{o}}}=6.4+2=8.4 \mathrm{~dB}$. The activity factor is $3 / 8+0.17$ dedicated control channel overhead $=0.545$. The load factor $\mathrm{n}_{\mathrm{DL}}=0.9$. The number of users $\mathrm{M}$ in the forward link are shown in Table 2.

By comparing Tables 1 and 2 it can be seen that the limitation in the capacity is set by the reverse link, where the number of subscribers is significantly smaller. Therefore the values from table 1 will be used for the capacity of the Air Ground system.

\section{CASE STUDY FOR GREEK AIRPORTS}

In order to implement the Air-to-Ground system for Greek Airports, where the base stations are located at the airports, a capacity study is provided for the three major airports in Greece, the Eleftherios Venizelos Airport of Athens, the Macedonia Airport of Thessalonica and the Nick Kazantzakis Airport of Heraklion. The distance between the Eleftherios Venizelos Airport of Athens (ATH) and the Nick Kazantzakis Airport of Heraklion (HER) is $308.65 \mathrm{~km}$ [11]. The distance between the Eleftherios Venizelos Airport of Athens (ATH) and the Macedonia Airport of Thessalonica (SKG) is 299.49 $\mathrm{km}$. Based on the above distances the size of the cells will be $\mathrm{R}=175 \mathrm{~km}$, so setting a cell centered at Athens and another centered at Heraklion will cover $2 \times 175=350 \mathrm{~km}$ and there is also overlapping so that the handover can be possible. The maximum height of the cell is chosen to be $\mathrm{h}=12000 \mathrm{~m}$ or 
TABLE 2. M VOICE USERS IN FORWARD LINK, $\mathrm{R}_{\mathrm{b}}=12.2 \mathrm{Kbps}, \mathrm{W}=3.84 \mathrm{MCPS}$, ACTIVITY FACTOR V=0.545, $\mathrm{n}_{\mathrm{UL}}=0.9, \mathrm{E}_{\mathrm{b}} / \mathrm{N}_{\mathrm{O}}=7 \mathrm{~dB}$, FOR R=50 KM, R=75 KM, $\mathrm{R}=100 \mathrm{KM}, \mathrm{R}=125 \mathrm{KM}, \mathrm{R}=150 \mathrm{KM}, \mathrm{R}=175 \mathrm{KM}, \mathrm{R}=200 \mathrm{KM}$ AND FOR VARIOUS VALUES OF H STARTING FROM 4 KM TO 12 KM

\begin{tabular}{|c|c|c|c|c|c|c|c|c|c|}
\hline $\begin{array}{c}\mathrm{h} \\
(\mathrm{Km}) \\
\mathrm{R} \\
(\mathrm{Km})\end{array}$ & 4 & 5 & 6 & 7 & 8 & 9 & 10 & 11 & 12 \\
\hline 50 & 242 & 221 & 202 & 191 & 181 & 173 & 164 & 159 & 154 \\
\hline 75 & 388 & 341 & 305 & 278 & 256 & 242 & 230 & 222 & 213 \\
\hline 100 & 676 & 523 & 450 & 391 & 359 & 338 & 314 & 299 & 283 \\
\hline 125 & 1336 & 897 & 699 & 555 & 520 & 473 & 434 & 389 & 374 \\
\hline 150 & 2438 & 1672 & 1177 & 927 & 771 & 675 & 556 & 529 & 487 \\
\hline 175 & 4483 & 3158 & 2281 & 1464 & 1242 & 975 & 842 & 762 & 686 \\
\hline 200 & 9759 & 5439 & 3445 & 2710 & 2255 & 1672 & 1380 & 1110 & 972 \\
\hline
\end{tabular}

almost 39344 feet, because commercial flights fly between the 25000 and 39000 feet [12-13]. In this way by choosing the maximum height of the cellular cell to be $h=12000 \mathrm{~m}$ all the possible heights of commercial flights are included. Three sectors will be used for every base station with antenna directions per 120 degrees, so that the coverage can approximate the cellular model we have used for the calculation of the OCIF. In Athens we will have the antenna pointing directions 50, 170 and 290 degrees. Thessalonica will have the same directions as Athens.

In Fig. 7 the map of Greece is illustrated showing the three airports along with the directions of the sectors and their base stations. In the radio-coverage charts of terrestrial mobile telecommunication systems, the focus is on land coverage and it is obvious the shadowing effect of electromagnetic radiation due to the morphology of earth's surface. Unlike this, in the Air-to-Ground system because the beams of the antennas aim high at the aircrafts, the electromagnetic shadowing which may exist in the low altitudes is not depicted, but the coverage appears at the height the aircrafts fly. In Fig. 7 the range of the $175 \mathrm{~km}$ is depicted in the direction of the sector and the total form of the coverage of each base station, it derives from the combination of the three radiation charts of the sectors. The final form of the coverage of the base station approaches the cylindrical structure of the cells.

In order to calculate the capacity in the forward link, $\mathrm{E}_{\mathrm{b}} / \mathrm{N}_{0}$ values in Table 3 are used, which were derived from the corresponding values for the terrestrial systems as depicted in [Table 11.21, 8], adding $2 \mathrm{~dB}$ because of the Air-to-Ground model. As $\mathrm{n}_{\mathrm{DL}}$ the value of 0.9 is being used everywhere.

TABLE 3: THE NUMBER OF USERS M FOR THE FORWARD LINK, AS A FUNCTION OF THE BIT RATE $R_{b}$ FOR VOICE, $\mathrm{R}=175 \mathrm{KM}, \mathrm{h}=12 \mathrm{KM}$ AND $\mathrm{n}_{\mathrm{D}}=0.9$. THE ACTIVITY FACTOR FOR VOICE SERVICE IS V=3/8+0.17 DPCCH OVERHEAD $=0.545$

\begin{tabular}{|c|c|c|c|}
\hline Eb/No (dB) & 8.4 & 7 & 7 \\
\hline $\mathrm{R}_{\mathrm{b}}$ (kbps) & 12.2 & 64 & 128 \\
\hline $\mathrm{M}$ & 497 & 71 & 35 \\
\hline
\end{tabular}

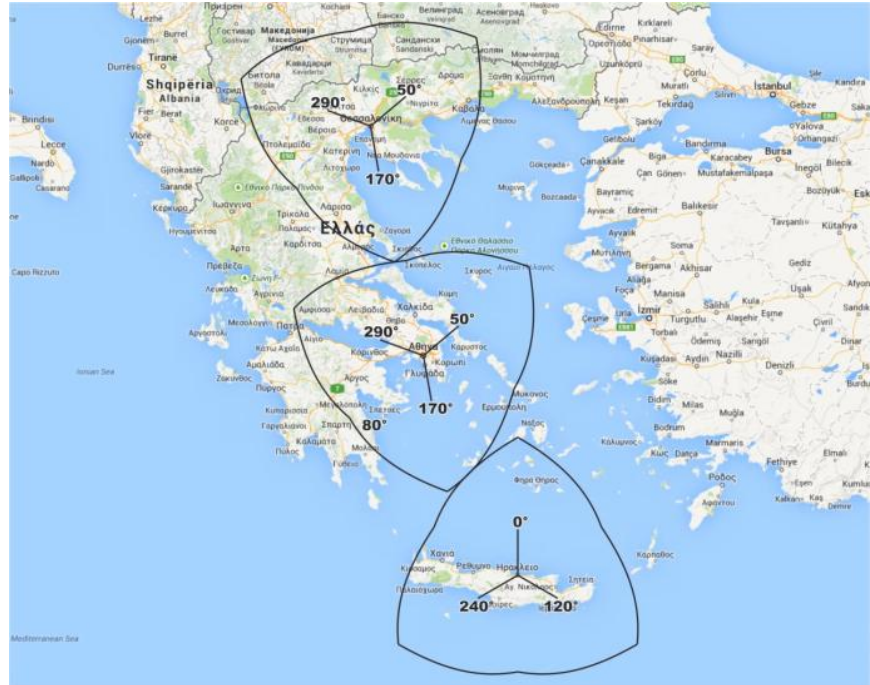

Fig. 7 Coverage map, $\mathrm{R}=175 \mathrm{~km}, \mathrm{~h}=12 \mathrm{~km}$.

In order to calculate the capacity in the reverse link, $\mathrm{E}_{\mathrm{b}} / \mathrm{N}_{\mathrm{o}}$ values in Table 4 are used as before. By comparing Tables 3 and 4 we can notice that the limitation of the system capacity for the case of the voice or the video call service which requires symmetrical traffic in both links, is taken by the reverse link, because this is where the lowest capacity exists. Therefore, the final capacity of the Air-to-Ground system is similar to the capacity of the reverse link, Tables 4 and 5. In Table 5 the number of users per cell and full capacity is presented for voice call $12.2 \mathrm{kbps}$ and video call services of 64 kbps and $128 \mathrm{kbps}$, which all concern symmetric traffic. The capacity of the cell is determined by the lowest value of the users for DL and UL.

TABLE 4: THE NUMBER OF USERS M FOR THE REVERSE LINK, AS A FUNCTION OF THE BIT RATE $\mathrm{R}_{\mathrm{b}}$ FOR $\mathrm{R}=175 \mathrm{KM}, \mathrm{h}=12 \mathrm{KM}$ AND $\mathrm{n}_{\mathrm{UL}}=0.9$.

\begin{tabular}{|c|c|c|c|}
\hline Eb/No $(\mathrm{dB})$ & 7.5 & 5 & 4,5 \\
\hline $\mathrm{R}_{\mathrm{b}}(\mathrm{kbps})$ & 12.2 (voice) & 64 & 128 \\
\hline M users per cell & 179 & 33 & 18 \\
\hline
\end{tabular}

\section{V.CONCLUSIONS}

From the results for the OCIF in the forward and the reverse link is confirmed that the OCIF increases logarithmically with the maximum height of the cell and reduces as long as the radius of the cell becomes longer. The capacity of the cell is inversely proportional of the OCIF and therefore as long as the maximum height of the cell increases the users become fewer. Moreover, for the same reason the capacity increases as long as the radius of the cell increases. The results above are reasonable because as long as the radius of the cell increases and its maximum height is relatively low, then due to curvature of the earth we do not have line of sight from the interfering cells and so the interference is low, therefore the capacity increases. For a cell radius of $175 \mathrm{~km}$, for the 3 major airports of Greece, it was found that we can 
service at the same time up to 179 voice subscribers per cell at bit rate $12.2 \mathrm{kbps}$ which reduces to 33 users for video call of $64 \mathrm{kbps}$ and in 18 for video call of $128 \mathrm{kbps}$.

TABLE 5: THE NUMBER OF USERS M FOR VOICE CALL AND VIDEO CALL SERVICES - SYMMETRIC TRAFFIC, AS A FUNCTION OF THE BIT RATE $R_{b}$ FOR DL AND UL, FOR R = $175 \mathrm{KM}, \mathrm{h}=12 \mathrm{KM}, \mathrm{n}_{\mathrm{UL}}=0.9 \mathrm{AND}_{\mathrm{DL}}=0.9$.

\begin{tabular}{|c|c|c|c|}
\hline Services & Voice call & \multicolumn{2}{|c|}{ Video call } \\
\hline $\begin{array}{c}\mathrm{R}_{\mathrm{b}} \text { (in kbps) for both } \\
\text { DL and UL }\end{array}$ & 12.2 & 64 & 128 \\
\hline M users per cell for DL & 497 & 71 & 35 \\
\hline $\begin{array}{c}\text { M users per cell for UL } \\
\text { Malue from DL and UL) }\end{array}$ & 179 & 33 & 18 \\
\hline Total users & 179 & 33 & 54 \\
\hline
\end{tabular}

\section{REFERENCES}

1. David W. Matolak, 3-D Outside Cell Interference Factor for an AirGround CDMA Cellular System, IEEE Transactions on Vehicular Technology, vol. 49, no. 3, pp. 706-710, May 2000.

2. J. Zhou, K. Ishizawa, and H. Kikuchi, Forward link performance of data packet transmission in an aeronautical CDMA cellular system, IEICE Trans. Commun., vol.E88-B, no.2, Feb. 2005, pp. 826-830.

3. J. Zhou; W. Pan; Y. Onozato, On the Capacity and Outage Probability of an Air-Ground CDMA Cellular System with Imperfect Power Control, Proceedings of International Conference on Wireless Communications, Networking and Mobile Computing, 2007, pp. 662 - 665.

4. M. C. Ramon, R. M. Rodrigez-Osorio, B. T. Ahmed, J. J. Iglesias Jimenez, Capacity of a UMTS System for Aeronautical Communications, Proceedings of 11th WSEAS Int. Conference on Communications, Agios Nikolaos, Crete, Greece, July 26-28, 2007.

5. B. Smida, V. Tarokh, Analysis of Interference in Air-to Ground CDMA Cellular Systems Under Idealized Assumptions, IEEE Transactions on Communications, vol. 59, no. 1, pp 258-267, Jan 2011.

6. Viterbi, Principles of Spread Spectrum Communication, AddisonWesley, 1995.

7. Ilias Peteinatos, WCDMA for Aeronautical Communications, Master Thesis, Brunel University, December 2014.

8. Harri Holma and Antti Toskala, WCDMA for UMTS - HSPA evolution and LTE, 4th Edition, John Wiley \& Sons, 2007.

9. http://www.iitg.ernet.in/engfac/krs/public_html/lectures/ee635/A3.pdf

10. B. T. Ahmed, M. C. Ramon and L. H. Ariet, The capacity of Air Ground W-CDMA system (UpLink Analysis), 13th IEEE International Symposium on Personal, Indoor and Mobile Radio Communications, 2002 .

11. http://www.prokerala.com/travel/airports/distance/ Airport Distance Calculator

12. http://www.boeing.com/boeing/commercial/cabinair/environmentfacts.p age

13. Commercial Airplanes, http://traveltips.usatoday.com/altitude-planeflight-100359.html What Is the Altitude of a Plane in Flight? 